\title{
ESTUDO DA COLEÇÃO DE LIVROS EDITADOS PELA SOCIEDADE DOS CEM BIBLIÓFILOS DO BRASIL DA BIBLIOTECA CENTRAL DA UNIVERSIDADE DE BRASÍLIA
}

\author{
Maria de Fátima Medeiros de Souza* \\ Maria Margaret Lopes**
}

\section{RESUMO}

O artigo enfatiza a coleção de livros da Sociedade dos Cem Bibliófilos do Brasil da Biblioteca Central da Universidade de Brasília. Essa coleção é formada por livros que pertenceram à quatro bibliófilos e constitui um conjunto importante para o estudo da Sociedade como um todo. A metodologia utilizada neste estudo parte das três fases propostas por Alberti (2005) para o estudo dos objetos das coleções museológicas. A primeira fase se refere à coleta e procedência; a segunda diz respeito à história do objeto dentro do acervo; a terceira contempla as exposições e as consultas do acervo pelo público.

\section{PALAVRAS-CHAVE}

Sociedade dos Cem Bibliófilos do Brasil; Biblioteca Central da UnB; Colecionismo bibliográfico.

\begin{abstract}
This paper investigates a book collection edited by the Sociedade dos Cem Bibliófilos do Brasil, which is kept in University of Brasília's Central Library. These books belonged to four different members of that bibliophile association, and they can help to understand the work of that group as a whole. The methodology of this paper was proposed by Alberti (2005) to study museum objects, and it consists of three steps. The first one deals with establishing the origin of the object and how it was gathered; the second one lays emphasis on the object's history in the institution where it's kept; and the third step concerns the exhibitions and public consultations.
\end{abstract}

\section{KEY-WORDS}

Sociedade dos Cem Bibliófilos; University of Brasília Central Library; book collecting.

\footnotetext{
* Doutoranda do Programa de Pós-Graduação em Arte/UnB e Mestra em Ciência da Informação/UnB. ** Possui graduação em Geologia pela Universidade de São Paulo (1980), mestrado em Educação pela Universidade Estadual de Campinas (1988), doutorado em História Social pela Universidade de São Paulo (1993) e Livre Docência em História das Ciências pela Universidade Estadual de Campinas (2002). Realizou estágio de doutoramento na Smithsonian Institution, Washington (1993), pós-doutoramento em História das ciências na University of Louisiana (EUA, 1997) com apoio da FAPESP e no Museu Etnográfico da Universidad de Buenos Aires (1998) com apoio da Rockefeller
} 


\section{Introdução}

Este artigo estuda o conjunto de livros editado pela Sociedade dos Cem Bibliófilos do Brasil (1943-1969) do Setor de Obras Raras da Biblioteca Central da Universidade de Brasília' a partir da metodologia apresentada por Alberti (2005) para o estudo dos objetos das coleções. Esse acervo da SCBB é formado pelos livros que pertenceram a quatro bibliófilos e ao todo 37 exemplares foram considerados neste estudo.

A Sociedade dos Cem Bibliófilos do Brasil foi dirigida por Raymundo Ottoni de Castro Maya (1894-1968) e editou 23 títulos da literatura brasileira. Os exemplares foram ilustrados com gravuras originais de artistas renomados. Esses livros possuíam uma edição limitada ${ }^{2}$ de exemplares que eram distribuídos para os cem membros e os demais eram doados para instituições culturais. Os sócios recebiam os exemplares impressos em folhas soltas e cada um encadernava de acordo com o seu gosto pessoal. São edições de luxo, nas quais o apreço pelos aspectos materiais como a arte da encadernação, ilustração e impressão são notórios (BARAÇAL; BANDEIRA; MOUTINHO, 2002).

A Biblioteca Central da Universidade de Brasília (BCE) mantém em seu acervo de obras raras exemplares de todos os títulos publicados pela SCBB. A coleção da BCE foi formada a partir da compra dos acervos particulares dos bibliófilos Ricardo Xavier da Silveira (?-1962), Pedro Nava (1903-1984), Carlos Lacerda (1914-1977) e Themístocles Marcondes Ferreira (?-1965). Os livros da BCE possuem encadernações de estilos variados e alguns exemplares contêm um excedente de gravuras e de desenhos que foram adquiridos pelos bibliófilos $^{3}$. Essas duas qualidades individualizam a coleção da BCE em relação às demais coleções da SCBB.

O conjunto de livros da Sociedade dos Cem Bibliófilos do Brasil da BCE ainda não foi estudado em profundidade. Embora se reconheçam as qualidades desse acervo, mostrado em exposições organizadas em galerias de Brasília, a construção dessa coleção ainda não foi alvo de um estudo significativo, para o qual este artigo pretende contribuir.

A abordagem proposta neste artigo parte da perspectiva de que o livro pode ser estudado como um objeto museológico - inclusive, ele frequentemente é usado em exposições - e, ao longo do tempo, o livro passou por mudanças nos materiais utilizados para sua fabricação. $O$ estudo desses aspectos permite que se avalie o livro a partir de uma perspectiva social e histórica. No que diz respeito aos acervos raros, caso dos livros da SCBB da BCE, os motivos que levaram essa Biblioteca a construir uma coleção dessa natureza passam tanto pelas características informacionais e literárias do livro, como também pelos aspectos materiais desse suporte (REIFSCHNEIDER, 2009).

Partindo dessa concepção museológica do livro, este estudo foi estruturado segundo a metodologia de Alberti (2005), que considera três fases para o estudo dos objetos das coleções.A primeira fase enfatiza a chegada dos objetos ao museu; a segunda fase trata da história dos objetos dentro das coleções dos museus e a terceira fase ressalta a exposição dos objetos museológicos.

\footnotetext{
' Sociedade dos Cem Bibliófilos do Brasil: SCBB; Biblioteca Central da Universidade de Brasília: BCE; Universidade de Brasília: UnB

${ }^{2}$ A tiragem dos exemplares variava: da $I^{\mathrm{a}}$ a $10^{\mathrm{a}}$ edição foram impressos 119 exemplares; da $I \mathrm{I}^{\mathrm{a}}$ a $2 \mathrm{I}, 120$ exemplares; a $22^{\mathrm{a}}$ publicação, com I 40 exemplares e a $23^{\mathrm{a}}$ publicação, com I 20 exemplares.

${ }^{3}$ Todos os exemplares da SCBB possuem gravuras originais, mas alguns bibliófilos adquiriram um excedente de gravuras e de desenhos nos leilões promovidos pela Sociedade. Os bibliófilos compravam essas obras e as encadernavam com o exemplar.Alguns livros do acervo de Obras Raras da BCE possuem obras excedentes que foram adquiridas pelos bibliófilos em leilões promovidos pela SCBB.
} 
Há uma tendência das disciplinas que se ocupam com o estudo da cultura material em propor novos olhares sobre o objeto. Mathieu (1987) afirmou que os mais diversos pesquisadores de áreas como Arqueologia, Museologia, História, Etnologia, Sociolinguística, Geologia e História da Arte propuseram uma leitura mais ampla do objeto por meio de um diálogo entre os procedimentos adotados por cada uma dessas disciplinas. Esses novos olhares entendem que a partir do aspecto material do objeto é possível descobrir relações mais profundas, como a atribuição de sentido, as interpretações e os valores simbólicos e culturais.

Os museus, os arquivos e as bibliotecas também lidam com o aspecto tangível do documento. Murguia (2009) destacou a urgência de se estudar com mais atenção as coleções dessas instituições e enfatizou o papel da biblioteca como um espaço propiciador de pesquisas, defendendo que o livro pode ser estudado a partir de sua informação escrita e também pela sua materialidade.

\section{Metodologia}

Os livros podem ser preservados tanto pelo seu conteúdo escrito, quanto pelo seu aspecto material e estético. No caso da coleção da Biblioteca Central da UnB, os livros da SCBB foram classificados como obras raras pelo fato de apresentarem características representativas de uma produção gráfica em que os livros eram bem acabados, feitos com papéis de qualidade, com encadernações trabalhadas e as páginas eram cuidadosamente impressas. Todos esses fatores levaram a analisar essa coleção por um viés que destacasse suas qualidades materiais, o que possibilita uma leitura museológica desses livros.

As abordagens mais comuns nos estudos museológicos se concentram na trajetória dos colecionadores e dos curadores ou na classificação dos objetos e sua exposição. Uma abordagem pouco explorada nesse campo e adequada a este estudo é a ênfase nos objetos das coleções. Alberti (2005) propôs três fases para se estudar esses objetos. A primeira se refere à coleta e à procedência. Nessa fase os objetos serão imbuídos de significados que irão nortear seu percurso até a instituição colecionadora, o museu, ou no nosso caso, a Biblioteca. A segunda fase se refere ao percurso do objeto na coleção. Nessa fase será evidenciada a história do objeto, que, muitas vezes pode adquirir novos significados dentro de uma coleção. $A$ terceira fase diz respeito à exposição dos objetos, momento no qual o objeto é avaliado e ressignificado pelo público (ALBERTI, 2005).

A primeira fase dessa análise parte da reunião da documentação que se refere à aquisição dos livros pela BCE. Em seguida levantou-se os dados sobre os bibliófilos proprietários dos livros adquiridos pela Biblioteca. No caso dos livros da SCBB, essa fase é particularmente marcante, já que os exemplares estavam associados aos seus proprietários e de alguma maneira esses livros refletiam os gostos desses colecionadores.

A segunda fase se refere à história dessa coleção dentro acervo da $\mathrm{BCE}$ e apresenta a trajetória dos livros da SCBB a partir de sua chegada à coleção do Setor de Obras Raras dessa Biblioteca. Para essa fase são destacados: o estado de conservação da coleção da BCE; aspectos da raridade desse acervo e os relatórios periódicos realizados pela Universidade de Brasília para mapear seu acervo de Obras de Arte.

$\mathrm{Na}$ terceira fase, considerou-se os catálogos das exposições em que os livros da SCBB da BCE foram mostrados e a consulta desse acervo pelo público. 
Também são apresentados aspectos das seguintes exposições: $O$ livro ilustrado brasileiro (199I), que ocorreu no Museu do Livro de Haia, Holanda; Imagem e Palavra: as publicações da Sociedade dos Cem Bibliófilos do Brasil, na Casa de Cultura da América Latina (2005) e o Catálogo Acervo de Arte: Universidade de Brasília.

Os objetos das coleções podem revelar diferentes aspectos, como: suas formas, materiais e técnicas, o meio social em que eram produzidos, o gosto e o estilo dos proprietários, o ambiente em que foram guardados, além do seu significado simbólico. (MATHIEU, 1987). Desta forma, enfatizar os objetos amplia o olhar sobre a coleção, pois devolve o papel de destaque a partir do qual outras pesquisas possam se construir.

\section{4 estudo da coleção de livros da Sociedade dos Cem Bibliófilos do Brasil da Biblioteca Central da Universidade de Brasília a partir das três fases de Alberti (2005)}

A Biblioteca Central é uma das principais instituições da Universidade de Brasília a guardar acervos. Segundo Oliveira e Ferreira (2013), o acervo da BCE é vasto e relevante para a UnB.

A BCE foi criada em 1962 e nesse período ela estava alocada em um dos andares do antigo prédio do Ministério de Educação e Cultura. As instalações definitivas da BCE só foram finalizadas em 1973. Sobre as primeiras aquisições de acervos bibliográficos, Fonseca (1973) mencionou as dificuldades enfrentadas nos primeiros anos de funcionamento da BCE. Como não havia verba da Universidade de Brasília destinada especificamente à aquisição de material bibliográfico, foi necessário firmar convênios com entidades particulares para que o acervo básico de algumas áreas pudesse ser construído.

Em relação às obras raras, Fonseca (1973) destacou o ano de 1963 como um período em que ocorreram aquisições importantes. Nesse período, a BCE adquiriu grandes acervos bibliográficos advindo de coleções particulares. Destacam-se as coleções de Homero Pires, com mais de 30 mil obras, muitas das quais eram raras.

É possível identificar uma prática colecionista na aquisição do acervo da Biblioteca Central, já que houve uma intenção de formar um acervo raro com obras relacionadas à produção bibliográfica brasileira, caso da aquisição dos documentos da Editora José Olympio, da coleção da Sociedade dos Cem Bibliófilos do Brasil e de exemplares da coleção Brasiliana. Segundo Fonseca (1973) Darcy Ribeiro pretendia constituir na BCE uma coleção Brasiliana.

No universo de obras de Arte que formam o acervo da BCE, encontra-se no Setor de Obras Raras a coleção da Sociedade dos Cem Bibliófilos do Brasil, que foi iniciada em 1963. Essa coleção abrange todos os títulos publicados pela SCBB, possui encadernações variadas, figurou em exposições organizadas em espaços culturais e é uma coleção relevante do acervo de Obras Raras da BCE.

\section{I Primeira fase}

Nesta primeira fase de análise são apresentados os quatro conjuntos de livros que formam a coleção da BCE, que pertenceram aos bibliófilos Ricardo Xavier da Silveira, Carlos Lacerda, Pedro Nava e Themístocles Marcondes Ferreira. São tratadas as formas de aquisição dessas coleções pela BCE, por meio da análise das documentações correspondentes. Também se ressalta, na biografia desses bibliófilos, as características relacionadas ao colecionismo de livros. 


\section{I. I A coleção de Ricardo Xavier da Silveira}

O bibliófilo Ricardo Xavier da Silveira formou-se em Direito e foi prefeito de Nova Iguaçu (RJ), entre 1936 a 1943. (GRYNSZPAN, 1990). Silveira foi o membro de número 13 na SCBB e seu nome figura entre os membros da Comissão Executiva em nove colofões das obras publicadas pela SCBB. Nas reuniões da Sociedade dos Cem Bibliófilos do Brasil, o nome de Silveira aparece em quatro atas, a de 23 de agosto de 1956, a de 12 de dezembro de 1957, a de 23 de janeiro de 1958 e a de 26 de junho de 1962 (ATA DAS REUNIÕES da Sociedade dos Cem Bibliófilos do Brasil, 1956; 1957; 1958; 1962).

Os jantares de apresentação dos livros da SCBB foram organizados no Jockey-Club do Rio de Janeiro, do qual Ricardo Xavier da Silveira foi membro ativo entre 1936 e 1952 (JOCKEY CLUB RIO. Disponível em: http://jcb.com.br/ noticias/22424/22424/. Acesso em: 26 out. 2015). Silveira também participou da Diretoria que organizou a produção da Sociedade dos Bibliófilos Brasileiros Cattleya Alba, em 1944 (DECLARAÇÃO DE MATRÍCULA na Confraria dos Bibliófilos brasileiros Cattleya Alba, 1944).

Traços da bibliofilia de Ricardo Xavier da Silveira podem ser deduzidos não somente pela sua participação ativa da Sociedade dos Cem Bibliófilos do Brasil e na Sociedade dos Bibliófilos Brasileiros, mas também a partir da presença de Silveira em uma disputa entre bibliófilos por livros raros em um leilão.

Advogados e intelectuais, bibliófilos de renome, comprimiam-se no armazém do leiloeiro Bricio, onde, desde há dois dias vem-se realizando o leilão da biblioteca do jornalista e bibliófilo Bricio de Abreu. O sr. Peixoto de Castro, um dos nossos mais ilustres advogados e bibliófilos, logo de inicio, pôs-se em campo em grandes batalhas com o bibliófilo Jeào Bellis. Enquanto os bibliófilos Hugo Vieira, Ricardo Xavier da Silveira, Francisco Barros Barreto, Eduardo Baheut, Celso da Rocha, Santana, Clovis Gaspar, general Mendes de Morais, Carlos Rizzini, Valter Cunha, Almeida e Silva, Miranda Fontes, José Goudar, Aguiar Moreira, Cori Novais, Enéas de Carvalho, Álvaro Araújo, Francisco Paiva, Ernesto Eliat e Jofé Pereira, disputavam arduamente edições raras e de luxo, que subiam a preços astronômicos. (JORNAL DIÁRIO DA NOITE, 28 de agosto de 1952, grifo nosso).

Essa reportagem também evidenciou o crescimento de colecionadores de livros raros no Brasil. Mindlin (1997) já havia mencionado que a bibliofilia nacional se estabeleceu a partir do século XX. Segundo essa reportagem, a disputa entre os bibliófilos por edições raras fez com que algumas obras chegassem a uma quantia exorbitante, caso de uma edição de Dom Quixote, de Miguel de Cervantes (I547-1616).

Sobre a raridade da biblioteca particular de Silveira, Fonseca afirmou:

[...] a Presidência da República (Juscelino Kubitschek) adquiriu a biblioteca particular de Ricardo Xavier da Silveira. Com isso passou a adquirir um belo exemplar da obra Rerum per octenium in Brasile de Barleus, uma das preciosidades da Brasiliana brasileira (FONSECA em entrevista à SILVA, 20I I: 73).

Dos 37 livros da SCBB que estão na Biblioteca Central da UnB, 17 provém da coleção de Ricardo Xavier da Silveira.A aquisição dos exemplares dessa coleção particular ocorreu em 1963, momento em que a UnB comprou diversas coleções para compor seu acervo.

A coleção de Ricardo Xavier da Silveira compreende todos os exemplares publicados pela Sociedade dos Cem Bibliófilos do Brasil entre 1944 e 1962, ou seja, os primeiros 17 livros publicados pelo grupo. Isso evidencia a participação de Silveira desde a criação da SCBB até o falecimento do bibliófilo, em 1962. 
Estudo da coleção de Ivros editados pela Sociedade dos Cem Bibliófilos do Brasil da Biblioteca Central da Universidade de Brasília

\section{I.2 A coleção de Carlos Lacerda}

Carlos Frederico Werneck de Lacerda (19/4-1977) foi jornalista, escritor e político. Carlos Lacerda foi opositor do governo do presidente Getúlio Vargas (I882-1954), ativo em diversos campos da política brasileira, atuou como vereador da cidade do Rio de Janeiro, em 1947, como deputado federal, de 1955 a 1959, e como governador do Estado da Guanabara, de 1960 a 1965. Carlos Lacerda também se destacou como escritor, ao todo foram mais de 30 títulos publicados (DULLES, 1992).

Grande parte dos arquivos pessoais de Carlos Lacerda foram doados pela sua família à Universidade de Brasília em 1979, no mesmo período em que a Universidade comprou sua biblioteca particular (INVENTÁRIO CARLOS LACERDA, 2000)

Sobre a aquisição do acervo e da biblioteca de Carlos Lacerda, um documento posterior mencionou detalhes do processo de compra, onde consta referência ao valor, sobre quem foram os avaliadores, uma descrição do material arquivístico e bibliográfico, entre outras informações (VALLE, 2 out. 1995).

A correspondência que tratou da aquisição da biblioteca de Carlos Lacerda pela BCE mencionou seu interesse por livros raros, o que pode indicar traços de sua bibliofilia. Os avaliadores da biblioteca de Carlos Lacerda destacaram a sua coleção de obras raras, que possuía exemplares antigos, dos quais se destaca Vida e fabulas do insigne fabulador grego, de Esopo (Lisboa, I684). Também foram realçadas pelos avaliadores algumas obras da coleção Brasiliana, como o exemplar Voyage au Brésil (Paris, 1869), escrito pelo naturalista Louis Agassiz e as obras: Memórias para a história da Capitania de São Vicente (Lisboa, I 797), escrita por Frei Gaspar da Madre de Deus e Sertum Paumarum brasiliensium (1903), do botânico João Barbosa Rodrigues (AQUISIÇÃO DA BIBLIOTECA de Carlos Lacerda, s/d).

O interesse de Carlos Lacerda pela confecção de livros de luxo o levou a fundar, na década de 1970, a Confraria dos Amigos do Livro (Knychala, I99I).

Os avaliadores também destacaram, na biblioteca de Carlos Lacerda, as obras da Sociedade dos Cem Bibliófilos do Brasil. Lacerda foi o membro de número 6 da SCBB. De acordo com as informações apresentadas nos documentos que avaliaram suas obras raras, Carlos Lacerda possuía a coleção completa dos livros da SCBB, mas, constam no acervo da BCE somente dois exemplares com o seu nome e número de inscrição impressos: Hino nacional brasileiro (1968) e $O$ compadre de Ogum (1969) (VALLE, 1995).

Contudo, há indícios de que Carlos Lacerda tenha adquirido exemplares que pertenceram a Themístocles Marcondes Ferreira. A obra Memorias posthumas de Braz Cubas, que está no acervo da BCE, pertenceu a Ferreira, membro de número 35 na SCBB. Entretanto, a obra referida apresenta carimbo da biblioteca de Carlos Lacerda, contendo ainda marcações que indicam sua compra, em 1979, mesmo ano em que a Biblioteca de Carlos Lacerda foi comprada (Fig. I)

\section{I.3 A coleção de Pedro Nava}

Pedro da Silva Nava foi médico e escritor. Nava formou-se em Medicina pela Universidade Federal de Minas Gerais, em 1928, nessa área, interessou-se pelo estudo da anatomia humana, foi membro da Sociedade Brasileira de Medicina e Cirurgia e exerceu a profissão até se aposentar, em 1969. Pedro Nava circulou entre as personalidades do Modernismo de Minas Gerais, uma de suas primeiras publicações foi o periódico A Revista, um trabalho resultante da parceria com Carlos Drummond de Andrade e outros autores. Entretanto, apesar de seu interesse pela literatura e pela poesia, suas principais obras foram publicadas a partir de 1970 (AGUIAR, 1998). 


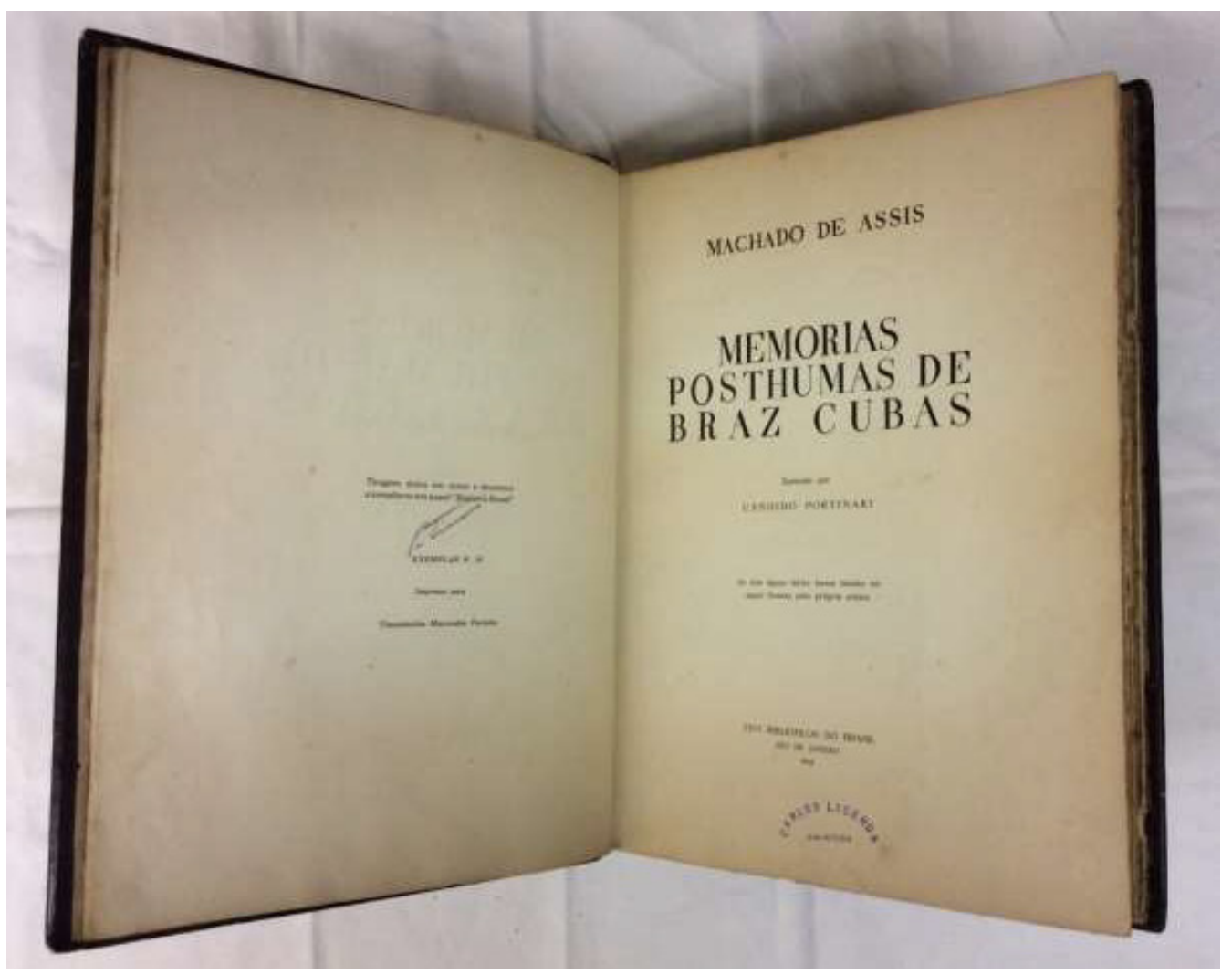

Figura I - ASSIS, Machado. Memorias posthumas de Braz Cubas, Sociedade dos Cem Bibliófilos do Brasil, 1944, exemplar No 35 de Themístocles Marcondes Ferreira. (Obra com carimbo de Carlos Lacerda). Fonte: Acervo de Obras Raras, Biblioteca Central da Universidade de Brasília.

Parte do acervo de Pedro Nava foi comprado pela Universidade de Brasília, em 1984. No processo de compra desse acervo, consta um parecer a respeito de seus exemplares raros. $O$ documento em questão foi elaborado pelo Bibliófilo, José Mindlin e pelo neurofisiologista, Aristides Pacheco Leão (1914-1993). Esse parecer mencionou os exemplares raros de Pedro Nava sobre a história da medicina, algumas primeiras edições de literatura brasileira e alguns exemplares da Sociedade dos Cem Bibliófilos do Brasil. O primeiro conjunto foi avaliado como o mais valioso da coleção. Esses dois pareceristas destacaram a raridade desse acervo e elencaram algumas obras importantes, dentre as quais é possível ressaltar Les Oeuvres de Me. André du Laures, Paris, 1646, obra que trata da anatomia humana e que foi ilustrada com gravuras na página do frontispício e que também possui capitulares e vinhetas ornamentadas (LEÃO; MINDLIN, I984).

Não é possível afirmar se a UnB de fato comprou todos os livros mencionados nesse parecer. $O$ que a avaliação mostra é o interesse de Pedro Nava por livros raros, sendo importante para a BCE a aquisição desse material.Além disso, esse documento também indicou a dimensão da biblioteca pessoal de Pedro Nava. A BCE, por exemplo, adquiriu por volta de I.800 títulos (MATERIAL BIBLIOGRÁFICO sem processamento técnico na Biblioteca Central, 19 dez. 1986).

Acerca dos exemplares da SCBB de Pedro Nava, encontram-se 13 volumes no acervo de Obras Raras da BCE com o nome e o número de Pedro Nava impressos. Nava possuía a inscrição de número 17 na SCBB segundo a listagem dos membros referente a última composição desse grupo.

Pedro Nava provavelmente ingressou na SCBB a partir de 1957, já que o primeiro título que contém seu nome impresso é Macunaíma, publicado nesse ano. A coleção de Pedro Nava é formada pelos I 3 últimos títulos publicados pela SCBB, entretanto, quatro exemplares que pertenceram à Themístocles 
Marcondes Ferreira apresentam marcações com a indicação da aquisição desses volumes pela BCE a partir da compra do acervo de Pedro Nava. Essas marcações foram encontradas nos seguintes exemplares: Canudos, Memórias de um sargento de milícias, Poranduba Amazonense e Cadernos de João. Sobressai o fato de haver edições que Nava já possuía, caso das duas últimas obras, que datam de 1961 e 1962, respectivamente.

\section{I.4 A coleção de Themístocles Marcondes Ferreira}

Themístocles Marcondes Ferreira foi diretor-presidente da Cia Editora Nacional, criada em 1925 pelo seu irmão Octalles Marcondes Ferreira (I8991972) e por Monteiro Lobato (1882-1948). A Cia Editora Nacional foi importante editora brasileira, também conhecida pelas publicações especializadas de livros didáticos e infantis, embora ao longo do tempo sua linha editorial tenha contemplado diversos tipos de publicações (HALLEWELL, 2005).

Segundo Hallewell (2005), Themístocles assumiu a direção da Editora Nacional após comprar uma parte das ações que pertenciam ao seu irmão, mas a administração real dessa empresa acabou sendo exercida por Octalles.

Themístocles também foi um dos fundadores da SNEL (Sindicato Nacional de Editores de Livros), órgão criado em 1940 e que ainda está ativo (ROMAIS, 2006).

Os dados sobre a biografia de Themístocles Marcondes Ferreira são escassos. Como descrito acima, Hallewell (2005) fez uma pequena menção a ele no capítulo dedicado à Octalles Marcondes Ferreira, grande empresário do ramo editorial brasileiro. Em virtude da falta de dados sobre Themístocles não é possível mensurar sua bibliofilia. Por outro lado, o interesse por livros pode ser identificado pela presença de Themístocles na fundação da SNEL, pela direção da Cia. Editora Nacional e pela sua participação da Sociedade dos cem Bibliófilos do Brasil.

Themístocles foi o membro de número 35 na Sociedade dos Cem Bibliófilos do Brasil, segundo informações impressas nos colofões das obras da BCE. Um aspecto que chama atenção para a coleção de Themístocles é o fato de ela conter publicações de períodos variados, diferente da coleção dos demais bibliófilos que abrangem um período contínuo de edições. A coleção de Themístocles que está na BCE contém a primeira publicação da SCBB, de 1944; a oitava publicação, que é de 1954; a décima publicação, de 1956; a décima quinta publicação, de 1961 e a décima sexta publicação, de 1962.A partir desses dados pode-se afirmar que Themístocles foi membro da SCBB entre 1944 e 1962. Provavelmente a coleção desse bibliófilo, que seria composta de 16 volumes publicados pela SCBB, tenha se dispersado. Uma prova disso são as marcas presentes nos livros da BCE que indicam a compra dos livros que pertenceram à Themístocles a partir dos acervos de Pedro Nava e de Carlos Lacerda.

Alberti (2005) já havia destacado que os objetos adquiridos pelos museus muitas vezes passam por diversos acervos particulares e se dispersam em inúmeras coleções. Esse parece ter sido o caso da coleção de Themístocles, além disso, não há documentos no arquivo da BCE referentes à negociação direta com os familiares de Themístocles.

\subsection{Segunda fase}

A segunda fase enfatiza a vida do objeto na coleção. A partir do momento em que é adquirido pela instituição, o objeto pode assumir diferentes sentidos ao longo de sua trajetória. Nesse caso, muitos objetos podem mudar de status ao longo de seu percurso na instituição e é por isso que essa fase é destacada por Alberti (2005) como o momento mais profícuo.

Para essa fase de estudo dos livros da Sociedade dos Cem Bibliófilos do Brasil, são apresentadas algumas notas gerais sobre o estado de conservação 
desses exemplares, sobre os aspectos que conferem raridade a esse acervo e também são estudados os relatórios periódicos da UnB para o levantamento de seu acervo de obras de arte, nos quais constam a coleção da SCBB da BCE.

\subsection{A raridade dos livros}

Ao longo dessa pesquisa não foram identificados nos arquivos da BCE documentos antigos referentes aos critérios adotados por essa Biblioteca para a definição das suas obras raras. Há somente um documento, de 1984, que menciona alguns dos critérios utilizados na época, assinala também como eram avaliados os livros selecionados para compor o conjunto das Obras Raras da BCE:

A Seção de Obras Raras, subordinada ao serviço de auxílio aos usuários, tem por função, promover a consulta e divulgação, reunir e preservar a coleção formada de: manuscritos, periódicos literários brasileiros e portugueses do século $\mathrm{XIX}$ e começo do século $\mathrm{XX}$, primeiras edições de obras escritas por autores renomados, assim como obras autografadas ou com dedicatórias dos mesmos, edições de luxo, livros de arte, edições diamantes, folhetos, jornais, ex-libris, mapas, etc.

[...] O material raro geralmente adquirido através de compra de grandes coleções particulares, passa pela Seção de Seleção onde é submetido a uma avaliação de acordo com os critérios de seleção de obras raras da Biblioteca. Esta avaliação conta com a colaboração de professores, bibliófilos e catálogos de obras raras (RELATÓRIO DOS SERVIÇOS - Serviços de aquisição, I984, grifo nosso).

Atualmente há um documento que norteia a seleção das obras raras, cuja metodologia usada contempla o "Limite histórico", o "Valor cultural”, os "Exemplares raros e/ou valiosos", as "peças raras e/ou valiosas" e os "formatos" das edições. A partir desses critérios adotados pela BCE, os livros da SCBB constituem acervo raro a partir do item que trata do "Valor cultural", que identifica para a composição das obras raras as "Edições limitadas, esgotadas, especiais e fac similares", as "Obras ilustradas por artistas de renome ou pelos próprios autores" e as "Encadernações de luxo, curiosas ou exóticas". O item que trata dos "Exemplares raros e/ou valiosos" também menciona características identificáveis nos livros da SCBB, que se referem à tiragem limitada e sobre o uso de materiais especiais na confecção dos exemplares. Também no item há um critério que realça as obras que possuam gravuras, caso dos exemplares da SCBB (CRITÉRIOS DE SELEÇÃO de Obras Raras BCE, s/d).

A documentação referente à aquisição dos acervos particulares dos quatro bibliófilos que formam a coleção da SCBB da BCE apresenta algumas referências sobre a aquisição de acervo raro. Fonseca (1973), como exposto anteriormente, mencionou a aquisição de obras para compor o acervo raro da BCE, em 1963. Esse autor também destacou o interesse da BCE em formar um acervo com obras da coleção Brasiliana descrita na Bibliographia Brasíliana por Rubens Borba de Moraes. Em 1963, também foi adquirido o acervo de Ricardo Xavier da Silveira, inclusive os exemplares da SCBB, foram destacados como uma raridade. Mas Fonseca (1973) não mencionou os critérios de raridade usados pela BCE.

Sobra a aquisição dos livros da SCBB de Carlos Lacerda, a documentação referente à negociação já destacava a raridade dessa coleção. $A$ coleção da SCBB foi apresentada em meio a obras antigas, grande parte do século XIX, muitas dessas obras também fazem parte da coleção Brasiliana, um dos grandes interesses da BCE. Esse parecer sobre a compra da biblioteca de Carlos Lacerda contou 
com a colaboração de Edson Nery da Fonseca, que conhecia o interesse de Darcy Ribeiro em construir uma coleção Brasiliana nessa Biblioteca (FONSECA, 1973).

A biblioteca particular de Pedro Nava foi avaliada por Aristides Pacheco Leão e por José Mindlin, esse documento de avaliação destacou como "obras especialmente valiosas" os exemplares Menino de Engenho e Macunaíma, ambos publicados pela SCBB. As demais obras dessa Sociedade também foram realçadas como valiosas (LEÃO; MINDLIN, 1984).

\subsubsection{Levantamentos periódicos}

Para traçar a trajetória dos livros da Sociedade dos Cem Bibliófilos do Brasil da BCE também foram consultadas listagens referentes aos levantamento periódico das obras de Arte que formam o conjuntos do patrimônio artístico e cultural da Universidade de Brasília.

Um dos primeiros inventários desse tipo foi realizado em 1997, servindo de referência para os levantamentos posteriormente realizados pela UnB. Nesse catálogo do Patrimônio Artístico da UnB, as obras da Sociedade dos Cem Bibliófilos do Brasil foram organizadas dentro da seção dedicada às gravuras, em uma subseção intitulada "Gravuras - álbuns e livros". As informações desse catálogo enfatizaram as gravuras da SCBB, apresentando o artista ilustrador, a quantidade de gravuras, assim como a especificação da técnica da gravura e a presença de obras excedentes adquiridas pelos bibliófilos que formam a coleção da BCE. O catálogo não indicou dados mais específicos sobre qual o exemplar consultado, a que bibliófilo pertenceram os livros e nem mencionou a existência de outros exemplares na coleção da SCBB da BCE. As obras da SCBB da BCE ocuparam grande parte da subseção "Gravuras - álbuns e livros" e dos 30 artistas listados, 20 foram ilustradores dos livros da SCBB (PATRIMÔNIO ARTÍ́STICO da UnB, I997).

O texto de apresentação do Patrimônio Artístico da UnB não mencionou se houve o interesse em mapear e descrever todas as obras de Arte da UnB. Existia, entretanto, a intenção de que o trabalho fosse um ponto de partida para futuros inventários. Passados mais de dez anos após a realização do catálogo do Patrimônio Artístico da UnB, entre os anos de 2006 e 2007, foi elaborado outro inventário dos bens culturais da UnB. O documento intitulado Relatório: atualização do Catálogo de Bens culturais da Universidade de Brasília é, de um modo geral, mais abrangente, contemplando novos setores da UnB.

Esse novo Relatório situou as obras da Sociedade dos Cem Bibliófilos do Brasil na categoria "Álbuns e Livros" e acrescentou dados em relação ao levantamento de 1997. $\mathrm{Na}$ publicação mais recente, alguns elementos como a identificação do bibliófilo a quem pertenceu o livro, a quantidade de exemplares, a tiragem e a ordem de publicação dos livros pela SCBB foram acrescentados. O Relatório também dedicou um campo exclusivo para essas obras da SCBB, da mesma forma que o levantamento de 1997 (RELATÓRIO:ATUALIZAÇÃO dos bens culturais da Universidade de Brasília, 2006/2007).

Outro levantamento dos livros da SCBB da BCE foi realizado pela produção da exposição Imagem e palavra: as publicações da Sociedade dos Cem Bibliófilos do Brasil, que correu em 2005, na Casa de Cultura da América Latina. O conteúdo desse mapeamento identificou algumas características dos livros da SCBB, tais como: título, ilustrador, ano de publicação, dimensão e numeração do exemplar. Nesse mapeamento também constavam a quantidade de exemplares que estavam no acervo da BCE, a que bibliófilo pertenceu o livro e se havia desenhos e/ou gravuras excedentes adquiridas pelos bibliófilos (EXPOSIÇÃO IMAGEM E PALAVRA: as publicações da Sociedade dos Cem Bibliófilos do Brasil, 2005). 
Esses relatórios periódicos contribuíram para traçar a trajetória da coleção de livros da Sociedade dos Cem Bibliófilos do Brasil, eles também podem indicar a relevância dessa coleção no acervo da BCE e para a Universidade de Brasília.

\subsubsection{Notas sobre o estado de conservação}

O estado de conservação dos livros da Sociedade dos Cem Bibliófilos da BCE também pode contribuir com a trajetória dessa coleção, pois ajudam a indicar a forma com que essas obras foram armazenadas no Acervo de Obras Raras e também como esses livros eram conservados por seus antigos proprietários.

Os livros da SCBB foram confeccionados, de um modo geral, com materiais de qualidade. A qualidade dos materiais usados nos exemplares da SCBB contribui com a conservação, mas esta também se relaciona ao modo como esses livros foram tratados pelos bibliófilos, uma vez que a encadernação pode influenciar a conservação dos exemplares. Outros aspectos também podem contribuir na conservação dos livros da SCBB, são os fatores relacionados ao armazenamento e ao manuseio dessas obras na Seção de Obras Raras.

Este estudo se desenvolveu a partir de um levantamento detalhado de todos os livros da SCBB da BCE, que foram organizados em um ficha com dados referentes ao estado de conservação desses obras. A partir desse mapeamento foram identificados alguns danos ao papel que se repetiam em boa parte dessa coleção. Os tipos mais comuns de deterioração encontrados nos exemplares da BCE foram o amarelecimento e o foxing.

Outros danos presentes no papel com que foram feitas as obras da SCBB advém do amarelecimento e da acidez. É o caso dos exemplares que apresentam muitas manchas e daqueles que tem bordas fragilizadas. Também foram identificadas outros danos nos papéis dessa coleção, tais como: sujidades, rasgos, dobras, entre outros.

Outro tipo de deterioração muito comum nos livros da SCBB da BCE é a migração, que se caracteriza pela "transferência da acidez de um material ácido para outro não ácido (ou com grau menor de acidez), quando os dois materiais estão juntos" (SPINELLI JÚNIOR, 1997: 77). No caso dos livros da SCBB, a migração ocorre principalmente nas páginas em que estão impressas as gravuras. Nessa coleção, muitas gravuras não contêm folha de proteção, cuja finalidade é de salvaguardar a imagem e contribuir com a conservação do livro (Fig. 2).

Também é comum encontrar livros da SCBB da BCE folhas de proteção com altos níveis de acidez, muitas vezes essas folhas foram encadernadas junto com o livro e há também casos em que essas folhas de proteção estão soltas nos exemplares inconsúteis. Nesse último caso, as folhas apresentam também dobras, rasgos e desgastes nas bordas.

A ausência de encadernação de alguns exemplares da coleção da BCE pode ocasionar risco à integridade desses livros. Como exposto anteriormente, a produção da SCBB entregava os livros impressos em folhas soltas aos bibliófilos. Como no modelo francês, o bibliófilo encadernava de acordo com seu gosto. $O$ que se verifica na coleção da BCE são muitos exemplares inconsúteis, boa parte deles apresenta uma sobretracapa de proteção, mas não há nenhum tipo de invólucro que evite a perda de páginas, assim como outras formas de danos. A ausência de encadernação pode ocasionar risco à integridade desses livros, considerando que uma das principais funções da encadernação é protegelos (GONÇALVES, 2008). 


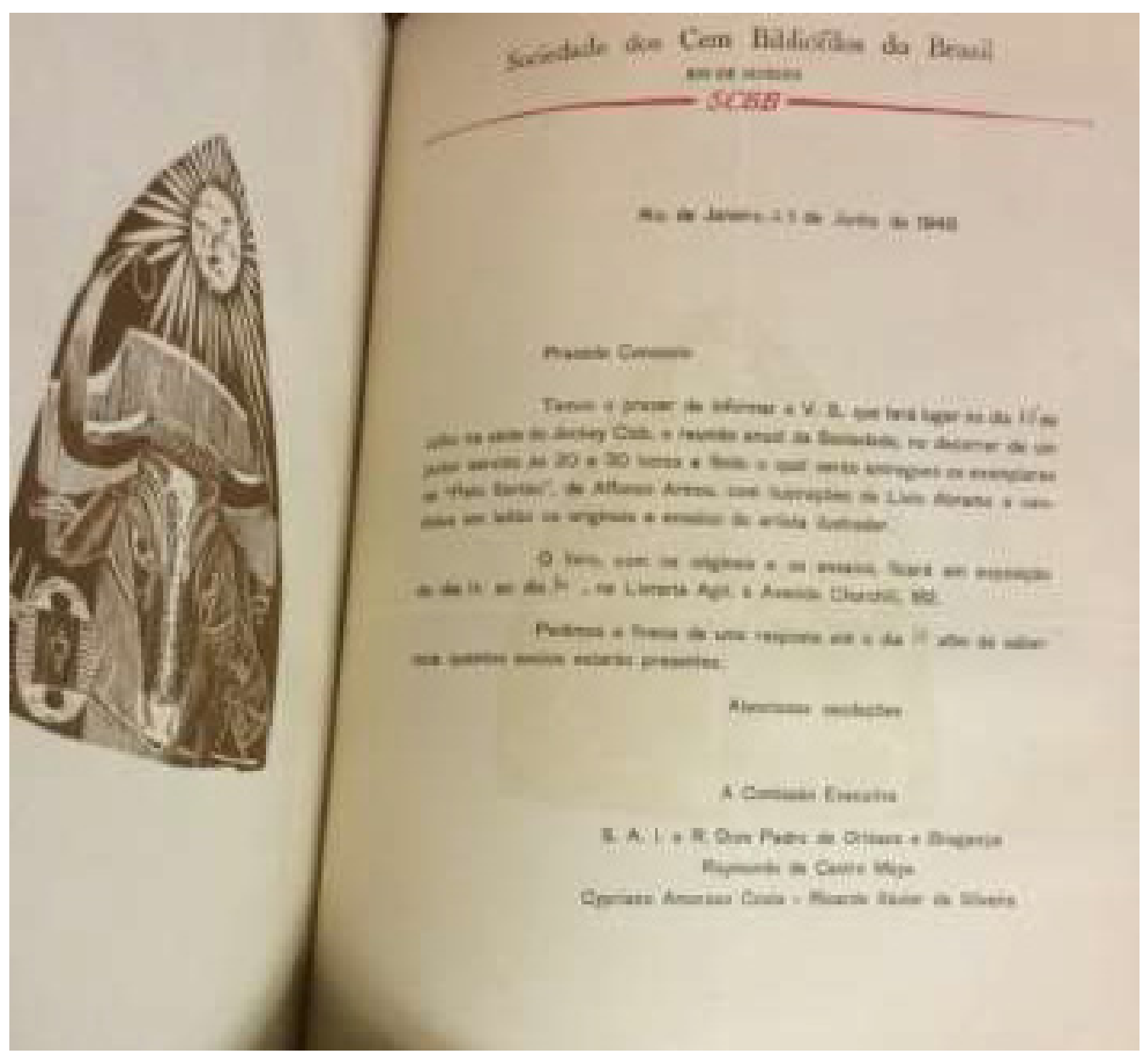

Figura 2 - ARINOS, Afonso. Pelo Sertão. llustração:ABRAMO, Lívio. Sociedade dos Cem Bibliófilos do Brasil, Exemplar N I 3 Ricardo Xavier da Silveira, 1946. (Exemplo de migração da gravura para a página seguinte). Fonte:Acervo de Obras Raras Biblioteca Central - BCE/UnB.

Nos volumes da SCBB da BCE que foram encadernados, há diversos tipos de danos que podem estar relacionados ao tipo de material usado na fabricação, assim como pela qualidade do trabalho do encadernador. Os materiais usados nas encadernações são variados, alguns livros receberam capas de couro, outros foram confeccionados com tecidos sintéticos e há também volumes com capas de papel comercial comum ou de papel marmorizado.

Os danos mais comuns nas obras da SCBB que foram encadernadas em couro são: desgastes na lombada, descoloração, pequenos rasgos e bordas fragilizadas. Há também os danos mais graves, que comprometem a estrutura da encadernação, que é o caso das lombadas parcialmente soltas.

As encadernações de tecido e de papel também apresentam desgastes, os mais comuns são: descoloração, sujidades, manchas, bordas fragilizadas, lombadas rasgadas, rasgos e perdas de partes da capa.

\subsection{Terceira fase: exposição e consulta dos livros da Sociedade dos Cem Bibliófilos do Brasil do acervo de Obras Raras da BCE}

A terceira fase se refere à exposição dos objetos e trata do modo como o público recepciona e estuda as coleções. Para a terceira fase do estudo dos livros da SCBB da BCE são apresentadas as exposições e as consultas desses livros pelo público. Essa coleção participou de exibições no acervo de Obras Raras da BCE, em espaços culturais brasiliense e em uma exposição internacional.Também são tratadas as consultas desses livros pelos usuários da BCE. 
No que se refere às consultas ao acervo de Obras Raras da BCE, Raphael Greenhalgh, chefe da seção de Obras Raras da BCE, em entrevista à Silva (20I I) pontuou uma média de 60 visitas por ano. A documentação relativa à consulta aos livros da SCBB aponta cinco visitas realizadas entre 2008 e 20I5. Certamente, os livros da SCBB foram mais visitados do que se tem documentado no arquivo do Acervo de Obras Raras da BCE. Os acessos que ocorreram no período de produção do catálogo Acervo de Arte: Universidade de Brasília (20I4), por exemplo, não foram registrados.

A seção de Obras Raras da BCE também recebe todos os semestres as turmas de Biblioteconomia que cursam o Estágio Supervisionado I, disciplina em que os alunos entram em contato com os vários setores da Biblioteca, entre eles o das Obras Raras. Segundo Raphael Greenhalgh, para essas turmas são separadas obras representativas do acervo, dentre elas alguns exemplares da SCBB. Outros cursos da UnB também visitam as Obras Raras, o setor recebeu seis turmas no decorrer do ano de 2015 e, assim como para os alunos da $\mathrm{Bi}$ blioteconomia, Greenhalgh mostrou os livros da SCBB ${ }^{4}$.

Em relação às exposições organizadas com os livros da SCBB da BCE, consta $\circ$ registro de quatro grandes mostras: $O$ livro ilustrado brasileiro (199I), organizada no Museu do Livro de Haia, Holanda; O livro de Arte Brasileiro - Sociedade dos Cem Bibliófilos do Brasil, no Espaço Cultural do Instituto de Artes/UnB (1993); O livro de Arte Brasileiro - Sociedade dos Cem Bibliófilos do Brasil no Museu de Arte de Brasília (1994) e a exposição Imagem e palavra: as publicações da Sociedade dos Cem Bibliófilos do Brasil, que ocorreu na Casa de Cultura da América Latina (2005). O Setor de Obras Raras também organiza periodicamente pequenas exposições com as obras de seu acervo, muitas das quais apresentaram os volumes da SCBB.

Acerca das exposições do Espaço Cultural do Instituto de Artes e do Museu de Arte de Brasília não foram encontrados os catálogos até a finalização desta pesquisa. Barrios (2008) mencionou essas exposições em seu artigo que tratou da coleção da SCBB da BCE:

[...] organizei no Espaço Cultural do Instituto de Artes/UnB em 1993, para a qual fiz uma curadoria e convidei especialistas em livros de arte, como a professora Catarina Helena Knychala para participar do projeto com uma palestra (BARRIOS, 2008,: 786).

Posteriormente, após ter visitado a exposição, um dos pioneiros do design brasileiro, Rogério Duarte, convidou-me para levar a exposição para o Museu de Arte de Brasília, da Secretaria de Cultura do Distrito Federal, onde foi montada em 1994 uma grande exposição com todas as edições realizadas pela Sociedade dos Cem Bibliófilos do Brasil. Em 2005, sendo coordenador de Artes Visuais da Casa da Cultura da América Latina organizei novamente outra mostra com as edições dos Cem Bibliófilos do Brasil com palestras de vários especialistas da área de literatura (BARRIOS, 2008: 787).

A exposição que ocorreu no Instituto de Artes, em 1993, e que depois foi reapresentada no Museu de Arte de Brasília, em 1994, recebeu a curadoria de Vicente Martinez, professor do Instituto de Artes da UnB. Na mostra de 1993, além da palestra com a professora de Biblioteconomia da UnB, Catarina Knychala, também foi organizada uma visita guiada com a artista Marília Rodrigues, que era especialista em gravura e que também foi professora do Instituto de Artes da UnB.

Para o estudo das exposições da coleção da SCBB, foram identificados os catálogos de $O$ livro ilustrado brasileiro e da mostra Imagem e palavra: as publicações da Sociedade dos Cem Bibliófilos do Brasil. Os catálogos das exposições, como

${ }^{4}$ Dados colhidos a partir de entrevista com o Chefe das Obras Raras Raphael Greenhalgh, 03 nov. 2015. 
destacou Alberti (2005), podem servir de referência para estudos de aspectos da relação do público com os objetos das coleções. Esses catálogos também oferecem informações que podem guiar essas apreciações e essas interpretações.

\subsection{Exposição O livro de Arte brasileiro}

A exposição $O$ livro de Arte brasileiro aconteceu no Museu do Livro de Haia, na Holanda, em 1991. Essa mostra foi organizada pela Ministério das Relações Exteriores do Brasil em parceria com a Universidade de Leiden e com o Museu do Livro de Haia.

O Museu do Livro de Haia foi um dos primeiros espaços do mundo a se dedicar à história do livro e também é considerado o maior museu com essa temática. $\mathrm{O}$ acervo desse Museu é amplo e compreende a produção de livros que vai do século $\mathrm{VI}$ até obras contemporâneas ${ }^{5}$. A exposição $O$ livro de Arte brasileiro foi a primeira mostra a apresentar livros brasileiros no Museu do Livro de Haia (KNYCHALA, I99I).

As obras selecionadas para participar da exposição $O$ livro de Arte brasileiro formam um conjunto que compreende diversos períodos de produção nacional de livro de arte. Como destacado por Knychala, a intenção dessa mostra foi constituir um panorama geral da produção nacional. Muitas instituições e colecionadores brasileiros cederam seus exemplares para essa mostra, apesar da dificuldade que teve a comissão organizadora para acessar alguns livros, como relatou Knychala. As principais instituições públicas que emprestaram seus exemplares para a exposição foram: a Biblioteca do Itamaraty do Rio de Janeiro, o Ministério das Relações exteriores e a Biblioteca Central da Universidade de Brasília. Cederam também seus exemplares, os colecionadores particulares como Catarina Knychala, Wladimir Murtinho (diplomata brasileiro) e José Mindlin (KNYCHALA, I99I).

A Biblioteca Central da UnB emprestou quatro obras da Sociedade dos Cem Bibliófilos do Brasil para essa exposição: Campo Geral e Hino Nacional brasileiro, que pertenceram a Pedro Nava; Pelo Sertão e O Rebelde, que pertenceram à Ricardo Xavier da Silveira. Ao todo foram 22 livros da SCBB exibidos nessa exposição, quatro vieram da coleção da BCE e 18 foram emprestados pela Biblioteca do Itamaraty (Rio de Janeiro). O único título da SCBB não exibido foi O ciclo do Moura.

4.3.2 Exposição Imagem e palavra: as publicações da Sociedade dos Cem Bibliófilos do Brasil

A exposição Imagem e palavra: as publicações da Sociedade dos Cem Bibliófilos do Brasil foi montada na galeria da Casa de Cultura da América Latina - CAL e ficou aberta à visitação de 15 de setembro a 13 de outubro de 2005 . Vicente Martinez Barrios (professor do Instituto de Artes - IDA/ UnB e então coordenador das galerias da CAL) foi o curador dessa exposição.

No dossiê correspondente à organização dessa mostra, apenas um documento faz a relação das obras expostas, e ainda assim de forma incompleta. Trata-se, provavelmente, do fragmento de uma listagem das peças em exibição, ordenadas cronologicamente de 1963 a 1969, com ressalva para a obra Pelo Sertão, que encerra a lista, apesar de não ter sido a última a ser publicada pela SCBB (EXPOSIÇÃO IMAGEM E PALAVRA: as publicações da Sociedade dos Cem Bibliófilos do Brasil, 2005).

${ }^{5}$ Disponível em: http://www.meermanno.nl/, acesso em: 26 dez. 2015. 


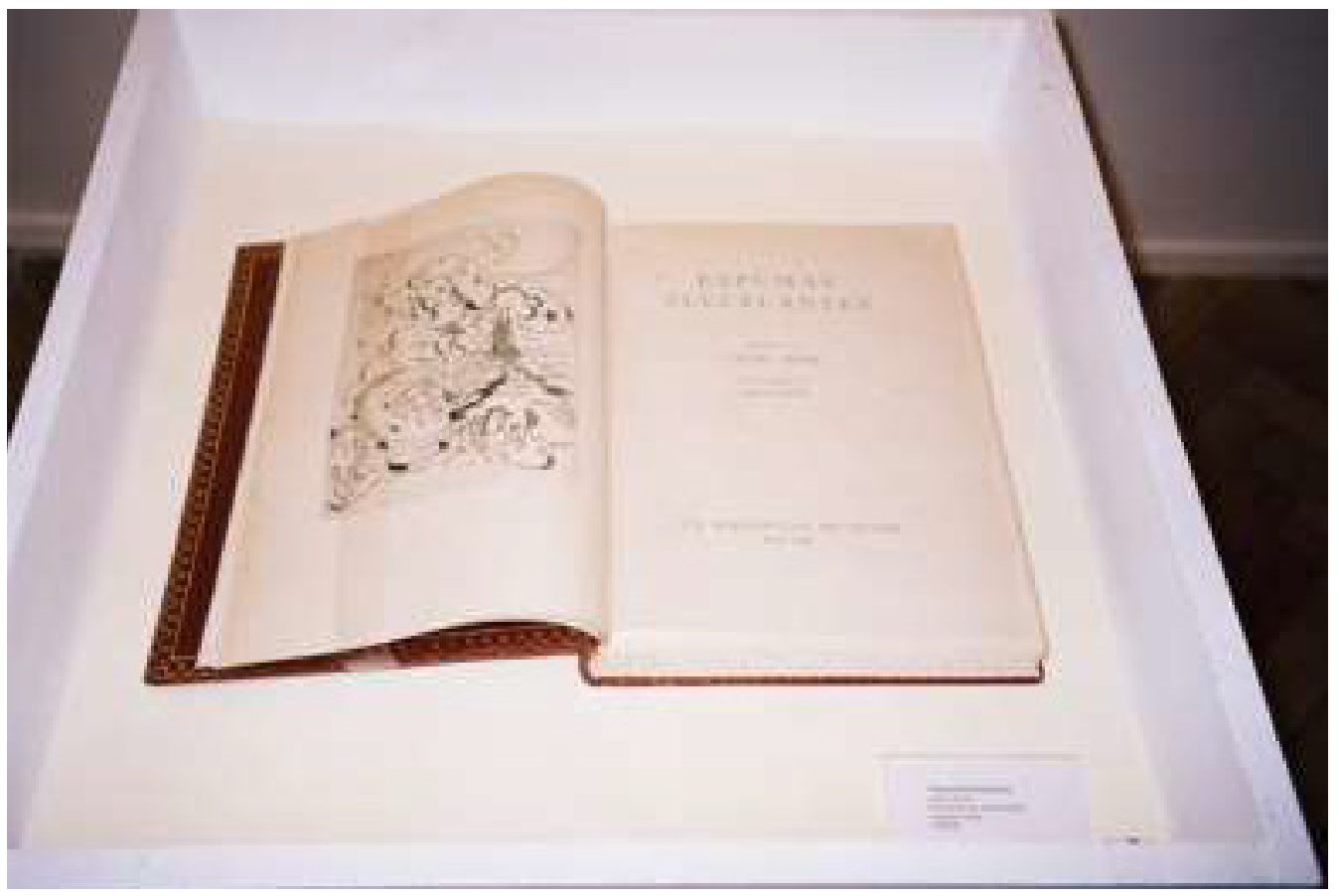

Figura 3 - Exposição Imagem e palavra: as publicações da Sociedade dos Cem Bibliófilos do Brasil, Casa de Cultura da América Latina - CAL/UnB, 2005.

Fonte:Arquivo do Acervo Casa de Cultura da América Latina - CAL/UnB.

Quanto ao desenho de montagem dessa exposição, alguns exemplares foram desmembrados e expostos nas paredes, outros foram colocados em cubos e mostrados em formato de livro encadernado. A coleção de livros da Sociedade dos Cem Bibliófilos da BCE, como já mencionado, apresenta livros encadernados e inconsúteis, o que possibilitou o tipo de montagem dessa mostra.A documentação referente a essa mostra indicou a forma com que algumas obras foram dispostas na galeria da CAL, há menção, por exemplo, de exemplares que foram expostos nas paredes. Nesse mesmo sentido, a documentação imagética dessa exposição mostra obras dispostas em paredes e livros encadernados expostos nos cubos (Fig. 3).

Para compor a exposição Imagem e palavra: as publicações da Sociedade dos Cem Bibliófilos do Brasil foram organizados três seminários a fim de discutir tópicos da literatura brasileira. Essas palestras foram organizados pela CAL com a finalidade de divulgar o acervo da UnB e fomentar a discussão sobre a literatura brasileira a partir dos autores publicados pela Sociedade dos Cem Bibliófilos do Brasil (PROJETO/EVENTO Seminário sobre Literatura brasileira: obras editadas pela “Associação dos Cem Bibliófilos Brasileiros”, 2005).

O foco de discussão desses Seminários foi no aspecto literário da coleção da SCBB, uma vez que todos os autores convidados estavam ligados aos estudos literários. $O$ aspecto artístico da coleção não foi abordado em profundidade, pois não havia entre os debatedores nenhum especialista das artes ou das áreas afins. O projeto desses Seminários também mencionou que o objetivo principal era fomentar a discussão sobre os autores brasileiros editados pela SCBB.

\subsubsection{Acervo de Arte: Universidade de Brasília}

O Catálogo do Acervo de Obras de Arte da Universidade de Brasília foi publicado em 2014 pela Editora da Universidade de Brasília. Participaram da comissão organizadora desse Catálogo profissionais e professores de diversos órgãos da Universidade de Brasília. 
Os trabalhos para a produção desse Catálogo foram iniciados em 2009 e um dos objetivos iniciais era o de que essa publicação fosse lançada como parte da comemoração dos 50 anos da Universidade de Brasília, em 2012. Estiveram à frente do projeto de produção desse Catálogo a Casa de Cultura da América Latina (CAL) e o Centro de Documentação (CEDOC/UnB).

Um dos objetivos desse Catálogo foi divulgar e colaborar com a conservação das Obras de Arte da UnB com a finalidade de preservar a memória institucional. Esse mapeamento se concentrou em três principais órgãos da UnB a guardar acervos de Arte: $O$ Instituto de Artes, a Biblioteca Central e a Casa de Cultura da América Latina (FERREIRA et al., 20I4).

Esse Catálogo foi dividido em três partes, a primeira contém textos críticos sobre o acervo e sobre os artistas que compõem o patrimônio artísticos da UnB; a segunda parte apresenta uma seleção de 50 imagens das obras de Arte da UnB e a terceira contém uma lista completa das obras que formam o acervo artístico da UnB. Os critérios usados na seleção das obras procuraram considerar a diversidade do acervo artístico, que contém obras de artistas, técnicas, formatos e temáticas variadas. A comissão que organizou esse catálogo procurou destacar as obras mais representativas dos vários acervos que formam o patrimônio cultural da Universidade de Brasília (FERREIRA et al., 20I4).

O texto de apresentação salientou a Sociedade dos Cem Bibliófilos do Brasil como uma das principais coleções do acervo da UnB:

É digno de nota que houve a necessidade de eleger algumas obras significativas que integram a Coleção dos Cem Bibliófilos, do Acervo das Obras Raras da Biblioteca Central - BCE/UnB, que é uma das parcelas mais representativas do acervo da universidade (FERREIRA et al., 20I4:I2).

O Catálogo Acervo de Arte contém dois textos críticos, escritos por Grace Maria de Freitas e Angélica Madeira.

No texto intitulado Patrimônio, Patrimônios da Universidade de Brasília a $D^{a}$ Grace Maria de Freitas, professora do Instituto de Artes da UnB, apresentou um panorama geral do acervo artístico da UnB, desde as obras dispostas nos espaços públicos do campus universitário até as obras de acesso restrito, como as que estão guardadas nos gabinetes dos prédios da Universidade e as que estão conservadas em acervos. Segundo essa autora, o acervo artístico da UnB foi constituído de modo diverso (FERREIRA et. al, 20l4).

O texto Acervo em busca de um museu, escrito pela prof ${ }^{a} \mathrm{Dr}^{\mathrm{a}}$. Angélica Madeira, também comentou a formação heterogênea do acervo artístico da UnB. O catálogo Acervo de Arte: Universidade de Brasília, segundo Madeira, procurou respeitar a variedade do acervo, destacando obras importantes que fizeram parte da história da UnB. Essa autora também destacou como uma coleção significativa do patrimônio da UnB, a coleção da Sociedade dos Cem Bibliófilos do Brasil (FERREIRA et al, 20I4).

Das 50 obras escolhidas pela Comissão de Preservação do Patrimônio Artístico para ilustrar o catálogo Acervo de Arte: Universidade de Brasília, ao todo foram selecionadas dez obras de artistas que ilustraram os livros da Sociedade dos Cem Bibliófilos do Brasil da BCE.

O catálogo Acervo de Arte: Universidade de Brasília mapeou por volta de mil obras, alguns artistas tiveram grande parte de sua produção listada, caso de Marília Rodrigues. Esse catálogo usou como referências as listagens anteriores dos levantamentos periódicos das obras de Arte que foram realizados pela UnB, em 1997 e em 2007, os quais foram analisados anteriormente. 


\section{Conclusão}

A coleção de livros da Sociedade dos Cem Bibliófilos do acervo de Obras Raras da Biblioteca Central da Universidade de Brasília constitui um conjunto de obras originais que podem ajudar a entender aspectos da produção de livros de luxo no Brasil. Como destacado, essa coleção é abrangente, apresentando todos os títulos publicados pela SCBB, alguns volumes apresentam encadernações variadas e há também os livros que possuem desenhos e gravuras excedentes que foram adquiridos pelos bibliófilos. Essas características individualizam os exemplares da BCE e fazem com essa coleção seja única e merecedora de estudos que enfatizem outros aspectos.

Como enfatizado neste artigo, na coleção da SCBB da BCE encontram-se livros que pertenceram à quatro bibliófilos. Esses colecionadores, de certa forma, refletem a composição da SCBB como um todo. Alguns participantes foram membros ativos da criação e concepção geral dos livros, caso de Ricardo Xavier da Silveira. Entre os membros da SCBB também estavam intelectuais e escritores brasileiros, caso de Pedro Nava. Também eram membros muitos políticos, caso de Carlos Lacerda e também de Ricardo Xavier da Silveira. Haviam integrantes desse grupo que trabalhavam em outras editoras brasileiras, caso de Themístocles Marcondes Ferreira e de Carlos Lacerda.

As três fases para o estudos dos objetos das coleções propostas por Alberti (2005) possibilitaram o estudo da coleção da SCBB da BCE a partir de uma ampla perspectiva: envolvendo os mecanismos de aquisição, a caracterização dos livros que pertenceram aos quatro bibliófilos citados, o modo com que o público se relaciona com esse acervo, as exposições em que esses livros foram mostrados, notas gerais sobre o estado de conservação, as encadernações e as Obras de Arte que agregam valor aos livros da BCE.

Os catálogos das exposições em que a coleção da SCBB da BCE foi mostrada evidenciam o interesse nos aspectos literários e artísticos dessa coleção. Em alguns momentos, entretanto, a relevância das ilustrações de artistas renomados brasileiros fez dessa coleção parte relevante das obras de arte da UnB. Essas exposições também evidenciaram o interesse em divulgar essa coleção não só no meio acadêmico, mas para um público mais vasto, fora da Universidade de Brasília.

\section{Referências}

AGUIAR, J. A. Espaços da memória: um estudo sobre Pedro Nava. São Paulo: EdUSP, 1998.

ALBERTI, S.J.M.M. Objects and the Museum. FOCUS - ISIS, 2005.

ATAS DAS REUNIÕES da Sociedade dos Cem Bibliófilos do Brasil. Pasta 100. Fonte:Arquivo Museu da Chácara do Céu - RJ.

BARAÇAL, A. B.; BANDEIRA, J.; MOUTINHO, S. Castro Maya Bibliófilo. Rio de janeiro: Editora Nova Fronteira, 2002.

BARRIOS,V.M. A modernidade do livro de arte brasileiro: a Sociedade dos Cem Bibliófilos do Brasil na coleção de Obras Raras da UnB, Florianópolis: $17^{\mathrm{a}}$ ANPAP, 2008. DECLARAÇÃO DE MATRÍCULA na Confraria dos Bibliófilos brasileiros Cattleya Alba. 24 ago. 1944, Pasta I02, Doc. 2, F I/I. Fonte:Arquivo do Museu Chácara do Céu - RJ.

DULLES,J.W.F.Carlos Lacerda:a vida de um lutador. Rio de Janeiro: Nova Fronteira, 1992. JORNAL DIÁRIO DA NOITE, 28 de ago. 1952. Fonte: Hemeroteca Digital - Biblioteca Nacional. 
Estudo da coleção de lvros editados pela Sociedade dos Cem Bibliófilos do Brasil da Biblioteca Central da Universidade de Brasília

MINDLIN, José; LEÃO,Aristides Leão Pacheco. Relatório Biblioteca de Pedro Nava, 1984. Fonte:Arquivo da Biblioteca Central/ UnB.

AQUISIÇÃO DA BIBLIOTECA de Carlos Lacerda, s/d. Fonte:Arquivo Biblioteca Central - BCE/UnB.

CRITÉRIOS DE SELEÇÃO de Obras Raras BCE. Fonte:Arquivo Biblioteca Central - BCE/UnB.

RELATÓRIO: ATUALIZAÇÃO dos bens culturais da Universidade de Brasília, 2006/2007. Fonte:Arquivo da Casa de Cultura da América Latina.

EXPOSIÇÃO IMAGEM E PALAVRA: as publicações da Sociedade dos Cem Bibliófilos do Brasil, 2005. Fonte:Arquivo Casa de Cultura da América Latina - CAL/UnB.

DECLARAÇÃO DE MATRÍCULA na Confraria dos Bibliófilos brasileiros Cattleya Alba, 1944, Pasta 102, Doc. 2, F I/I. Fonte:Arquivo do Museu Chácara do Céu - RJ.

GRYNSZPAN, M. Os idiomas da patronagem: um estudo da trajetória de Tenório Cavalcanti. Rio de Janeiro, FVG, CPDOC, I semestre, 1990.

HALLEWELL, L. O livro no Brasil: Sua história. 3ª Ed. São Paulo: EdUSP, 2005.

REIFSCHNEIDER, O. D. B. O livro como objeto museológico. Brasília: RICI: R. Ibero-amer. Ci.Inf.v.2, ago. /dez., 2009.

MATHIEU, J. L'object et ses contextes. Bulletin d'histoire de la culture matérielle 26, pp. 7-17, 1987.

MURGUIA, E. I. O colecionismo bibliográfico: uma reflexão sobre o livro para além da informação. Bahia:VIII ENANCIB, 2009.

OLIVEIRA, E. D. G.; FERREIRA, A.W. A construção de um acervo: princípios e estratégias de classificação. São Paulo: UNESP, v. 9, p. 96-I I 2, 2013.

FONSECA, E. N. Biblioteca Central da Universidade de Brasília: história com um pouco de doutrina e outro tanto de memórias. Brasília: R. Bibliotecon, 1973.

MINDLIN, J. E. Uma vida entre livros: reencontros com o tempo. São Paulo: Companhia das Letras, 1997.

SILVA, F. Critérios de seleção de Obras Raras adotados em bibliotecas do Distrito Federal.

Dissertação (mestrado). Brasília: Universidade de Brasília, Faculdade de Ciência da Informação, 20II.

INVENTÁRIO CARLOS LACERDA, 2000, p. 2 I. Fonte:Arquivo Biblioteca Central - BCE/UnB.

VALLE, Clarimar Almeida. Divisão de Coleções Especiais - BCE/ UnB, 2 out. 1995. Fonte:Arquivo Biblioteca Central - BCE/UnB.

KNYCHALA, C. H. O Livro de arte brasileiro. Rio de Janeiro: Presença, 1981.

MATERIAL BIBLIOGRÁFICO sem processamento técnico na Biblioteca Central, 19 dez. 1986. Fonte:Arquivo Biblioteca Central BCE/ UnB.

ROMAIS, S. E. A literatura como fato social: instâncias e instituições que constroem o literário. Paraná: Universidade Estadual de Maringá Centro De Ciências Humanas, Letras e Artes Programa de Pós-Graduação em Letras (Mestrado), 2006. SPINELLI JUNIOR, J. A conservação de acervos bibliográficos \& documentais. Rio de Janeiro: Fundação Biblioteca Nacional, 1997.

GONÇALVES, E. M. Estudo das estruturas das encadernações de livros do século XIX na coleção Rui Barbosa: Uma contribuição para a conservação - restauração de livros raros no Brasil. Dissertação. Escola de Belas Artes - UFMG, Belo Horizonte, 2008. 
FERREIRA,A.W. et. al. Acervo de Arte:Universidade de Brasília. Brasília: Editora da Universidade de Brasília, 2014.

PROJETO/EVENTO Seminário sobre Literatura brasileira: obras editadas pela -Associação dos Cem Bibliófilos Brasileiros, 2005, p. 2. Fonte:Arquivo do Acervo Casa de Cultura da América Latina - CAL/UnB.

PATRIMÔNIO ARTÍSTICO da UnB, 1997. Fonte:Arquivo da Casa de Cultura da América Latina - CAL/UnB. 